\title{
Evaluation of Discrete and Passive Sampling (Diffusive Gradients in Thin-films - DGT) Approach for the Assessment of Trace Metal Dynamics in Marine Waters - a Case Study in a Small Harbor
}

Ana-Marija Cindrić, ${ }^{1}$ Neven Cukrov, ${ }^{1}$ Gaël Durrieu, ${ }^{2,3}$ Cédric Garnier, ${ }^{2,3}$ Ivanka Pižeta, ${ }^{1}$ Dario Omanović ${ }^{1, *}$

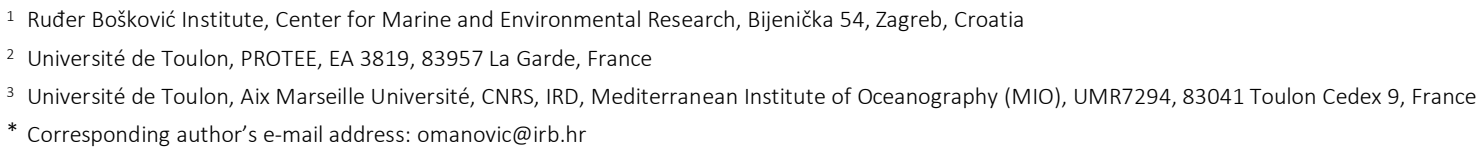

RECEIVED: May 12, 2017 * REVISED: June 19, 2017 * ACCEPTED: June 20, 2017

\section{INTRODUCTION}

$\mathbf{T}$ RACE metals in the aquatic environment are naturally occurring constituents. They can enter into the aquatic system through erosion processes, ${ }^{[1]}$ but could be also released by different human activities that have great impact on coastal areas and can directly or indirectly contribute to contamination. ${ }^{[2-4]}$ In natural waters, trace metals exist in different physical forms and chemical species, which regulate their biogeochemical cycle ${ }^{[5]}$ as well as their potential toxicity for organisms. Due to the complexity of the aquatic environment, the speciation of trace metals is a very challenging, and different approaches have been applied. ${ }^{[5-8]}$ The most common approach providing sufficient information to understand general behavior of trace metals distribution is based on discrete sampling and the measurement of dissolved and total metal concentrations. ${ }^{[2,4,9]}$ However, for a greater understanding of the behavior and the interactions of trace metals with other constituents (including biota), specific techniques were developed and widely applied, providing valuable information on the trace metal speciation. ${ }^{6,10-17]}$ Bioavailability of trace metals is of primary concern when considering if trace metals serve as nutrients or as toxicants. ${ }^{[10,11,18]}$ According to European Water Framework Directive ${ }^{[19]}$ some trace metals $(\mathrm{Cd}, \mathrm{Pb}, \mathrm{Hg}$ and $\mathrm{Ni}$ ) are considered as of priority concern and measurement of their bioavailability is suggested either indirectly by modeling of their speciation or directly by utilizing specific measurement methodology. ${ }^{[6,20-22]}$ Due to the generally 
very low concentrations of trace metals in natural waters, techniques for their determination and speciation need to have high sensitivity, precision and accuracy. Passive sampling is an alternative and promising approach for trace metals monitoring and operational speciation. The most widely used is diffusive gradients in thin-films (DGT) technique which pre-concentrate metals of interest in-situ, during a deployment period. It has a satisfactory detection limit, and allows measurement of free ions and labile organic/inorganic complexes in water, soil or sediment. ${ }^{[7,8,10,11,21,23]}$ Since DGTs can be deployed in water over a defined period of time (from a few days to approximately two months), the resulting concentration represents the time weighted average (TWA) concentration of reactive species. ${ }^{[7,24]}$ Concentrations determined by this technique are known as DGT-labile and represent potentially bioavailable metal forms. ${ }^{[25]}$ Currently, the only methodology which respects metal speciation for the assessment of the water quality in fresh waters is Biotic Ligand Model (BLM) ${ }^{[26]}$ introduced by the US Environmental Protection Agency (US EPA) for the estimation of water quality criteria on $\mathrm{Cu}$. [27]

One of the major pollution sources in coastal waters are shipyards, harbors and marinas. ${ }^{[28,29]}$ Activities in these areas may have a great impact on coastal line as various contaminants like trace metals, antifouling paints and particles, oil, solvents or water residues from ship hull washing are discharged in the water. ${ }^{[28]}$ Biofouling is a big problem for both, small and large vessels leading to reduction of speed and increased fuel consumption. ${ }^{[30]}$ In shipyards, harbors and marinas local sources of contamination are $\mathrm{Cu}$ and $\mathrm{Zn}$ stemming from paint waste. ${ }^{[2,31,32]}$

The purpose of this study is to evaluate a multimethodological approach, consisting of classical discrete grab sampling, passive sampling using DGT technique and a chemical speciation modeling, for the assessment of the spatial and temporal distribution, as well as the operational speciation of trace metals in a small harbor (Sušak port in Rijeka harbor, Croatia, Adriatic Sea) having various transshipment activities and which is also under permanent influence of freshwater inflow receiving various forms of waste.

\section{WORKING METHODOLOGY AND ANALYTICAL TECHNIQUES}

\section{Study Site}

A subdivision of Rijeka harbor, named Sušak port, was selected as the study site. Specifically, based on our observations during study, the port served primarily for transshipment of various metallic debris for recycling, large

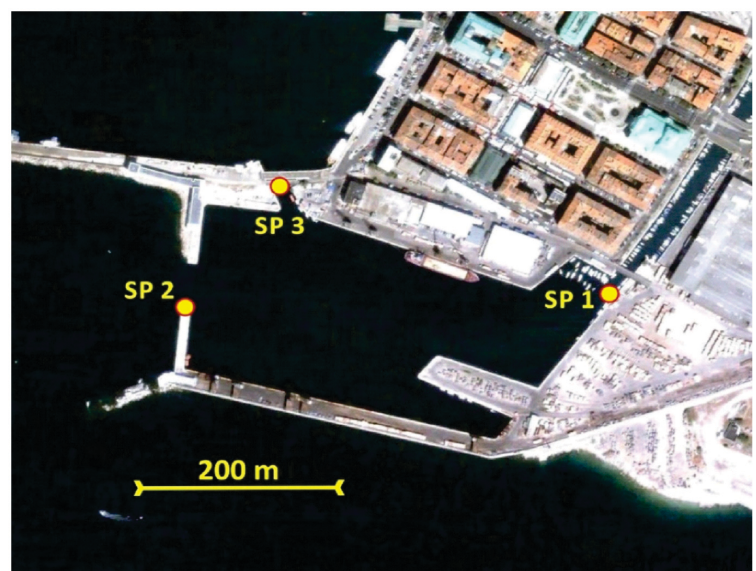

Figure 1. Satellite image (GoogleEarth) of the Sušak port with marked three sampling sites.

stone plates, wood material (timbering) and other smallscale transshipments. Three sampling sites (SP1, SP2 and SP3) were selected within the port to cover all relevant inputs/outputs allowing a more accurate assessment of anthropogenic sources within the port (Figure 1).

Sampling site SP1 was located at the connection with the "Dead channel" (freshwater input by the branch of Rječina River) in which numerous small local vessels were berthed, SP2 was at the main entrance to the port with the direct exposure to the "open sea" and SP3 was positioned at a small bridged passage, serving as a link to the bigger part of Rijeka harbor (separated from the open sea by $\approx 2 \mathrm{~km}$ long breakwater). The flow of surface water at SP1 site was consistently toward the sea, while at sites SP2 and SP3 the flow direction of water mass changed relative to the tide.

\section{DGT Devices and Survey Strategy}

The commercially available DGT devices used for this study (DGT Research Ltd., Lancaster, UK) consisted of a pistonlike plastic holder enclosing a cellulose-acetate filter ( 0.45 $\mu \mathrm{m}$ pore-size) as a protective membrane, polyacrylamide as a diffusive gel layer (thickness $0.8 \mathrm{~mm}$ ), and a Chelex-100 as a resin. ${ }^{[8]}$ DGT devices were mounted within the PVC holder and deployed aside of the dock at a depth between 0.5 and $1 \mathrm{~m}$. To improve reliability of the analysis, DGT devices were deployed in duplicate (see Figure S1 in supporting materials). A temperature data-logger Sensus Ultra (ReefNet Inc., SAD) was mounted on each DGT holder for continuous measurement of temperature (15 min resolution). The average temperature was used to correct diffusion coefficients. A deployment period of approximately two weeks (exact time in hours was determined for each deployment site and period) was chosen as a compromise of frequency of deployment/analysis (site is remote from the main laboratory) and expected biofouling 
of DGT filter membrane (if extensive, biofilm reduces the efficiency of the DGT device). Although evident (Figure S1), it is assumed that weak biofouling did not have significant impact on the accumulation process of trace metals. Overall, DGT devices were deployed during 10 separate two-weeks periods (January - May).

Discrete samples were taken at the time of DGT devices exchanges for measurements of dissolved trace metals and dissolved organic carbon (DOC). Samples were collected at DGT-devices depth with the acid/MQ (ASTM type I, $18.2 \mathrm{M} \Omega \mathrm{cm}$ ) precleaned 1 L FEP (Fluorinated Ethylene Propylene) bottles mounted on a telescopic arm. After sampling, samples were stored in a portable refrigerator until further treatment (filtration) in the laboratory within 5-6 hours. Two discrete samples (at the time of deployment and the time of retrieval of DGT devices) were analyzed for each two-weeks DGTdeployment period, and the average concentration of trace metals was used for comparison with DGT-labile concentrations.

\section{Preparation of Samples}

For the determination of dissolved fraction of trace metals, seawater samples $(250 \mathrm{~mL})$ were filtered under the nitrogen pressure through $0.45 \mu \mathrm{m}$ cellulose-nitrate filter (Sartorius). Filtered samples were acidified by trace metal grade nitric acid (TraceSelect, Fluka) and irradiated directly in the FEP bottles (Nalgene) with UV-light (150 W low pressure Hg lamp; Hanau, Germany) for $24 \mathrm{~h}$ in order to decompose natural organic matter which could influence analytical determination of trace metals done by voltammetric technique. For the analysis of dissolved organic carbon (DOC), a subsample $(20 \mathrm{~mL})$ of filtered seawater was collected at the end of filtration in precalcinated $24 \mathrm{~mL}$ glass tube equipped with Teflon/silicon septum (Wheaton). These samples were preserved by the addition of sodium azide ( $\mathrm{NaN}_{3}, 1 \mathrm{mM}$ final concentration) and stored with refrigeration until analysis.

Upon remove of DGT devices from the holder, they were rinsed with $\mathrm{MQ}$ water and stored in properly marked zip plastic bags at $+4{ }^{\circ} \mathrm{C}$ until further processing. Dismounting of the DGT device and retrieval of DGT Chelex-100 resin gel was performed in the laboratory under controlled atmosphere (Class-100 laminar bench). Resin gel was transferred into the pre-cleaned polyethylene vials $(2 \mathrm{~mL}$, Eppendorf) and eluted in $1.5 \mathrm{~mL}$ of $1 \mathrm{M}$ ultra-clean $\mathrm{HNO}_{3}$ for at least $24 \mathrm{~h}$. Three undeployed DGT devices were treated in the same way and used as blanks (average value was used for processing).

\section{Analytical Methods}

Concentrations of dissolved trace metals in discrete seawater samples were determined by differential pulse stripping voltammetry: anodic (DPASV) for $\mathrm{Zn}, \mathrm{Cd}, \mathrm{Pb}, \mathrm{Cu}$ and adsorptive cathodic (DPAdCSV) for $\mathrm{Ni}$ and Co. Measurements were carried out on Autolab (EcoChemie) potentiostats ( $\mu$ Autolab2 or PGSTAT128N) controlled by GPES 4.9 software in a three-electrode cell (663 VA Stand, Metrohm). $\mathrm{Ag}|\mathrm{AgCl}|$ sat. $\mathrm{NaCl}$ electrode was used as the reference electrode, a Pt wire as the auxiliary and a static mercury drop (SMDE) as the working electrode. The specific measurement procedures followed published protocols. ${ }^{[2]}$ Concentrations of trace metals were determined by means of standard addition method. A certified "Seawater Reference Material for Trace Metals" - NASS-5 (NRC CNRC) was used for validation of the analysis. All determined metal concentrations were within the certified limits. The precision of single analytical measurements was within 10 $\%$ of measured concentrations.

TOC-VCSH analyzer (Shimadzu) was used for determination of DOC concentrations. Calibration was performed with hydrogenophtalate (Shimadzu) standard solution, with an accuracy of $0.02 \mathrm{mgC} \mathrm{L}^{-1} \cdot{ }^{[4,16]} \mathrm{A}$ satisfactory accuracy of analyses was validated using certified reference material MISSIPPI-03 (Environment Canada).

Multielemental analysis in DGT eluates (at $3 x$ dilution) was performed by High Resolution Inductively Coupled Plasma Mass Spectrometer (Element 2, HR ICPMS, Thermo, Bremen, Germany). External calibration and Indium (In) as an internal standard (IS) were used for analyses. Quality control (QC) of HR ICP-MS measurements were performed by the determination of element concentrations in "River Water Reference Material for Trace Metals" (SLRS-5, National Research Council Canada). A good agreement with the certified data was obtained for most elements (within $10 \%$ of certified values).

DGT-labile concentrations in water were calculated according to instructions provided by DGT Research Ltd. and as described by Davison and Zhang. ${ }^{[8,33]}$ Effective diffusion coefficients (determined in separate controlled experiments) operational for brackish/seawater conditions were used for all calculations. ${ }^{[2,34]}$

Error bars in figures represent the upper and the lower measured dissolved metal concentrations for that deployment period (samples taken at the beginning and at the end of deployment period) and/or DGT-labile concentrations of metals measured in each of the two DGT devices. If not visible, error bars are within the size of the symbol. Note that these "error bars" are not related to any uncertainty.

\section{Speciation Modelling}

Prediction of trace metal speciation at DGT deployment sites was made by Visual MINTEQ ver. 3.1 (VM). ${ }^{[35]}$ A NICADonnan model (NICA) is applied for modelling of metal - 

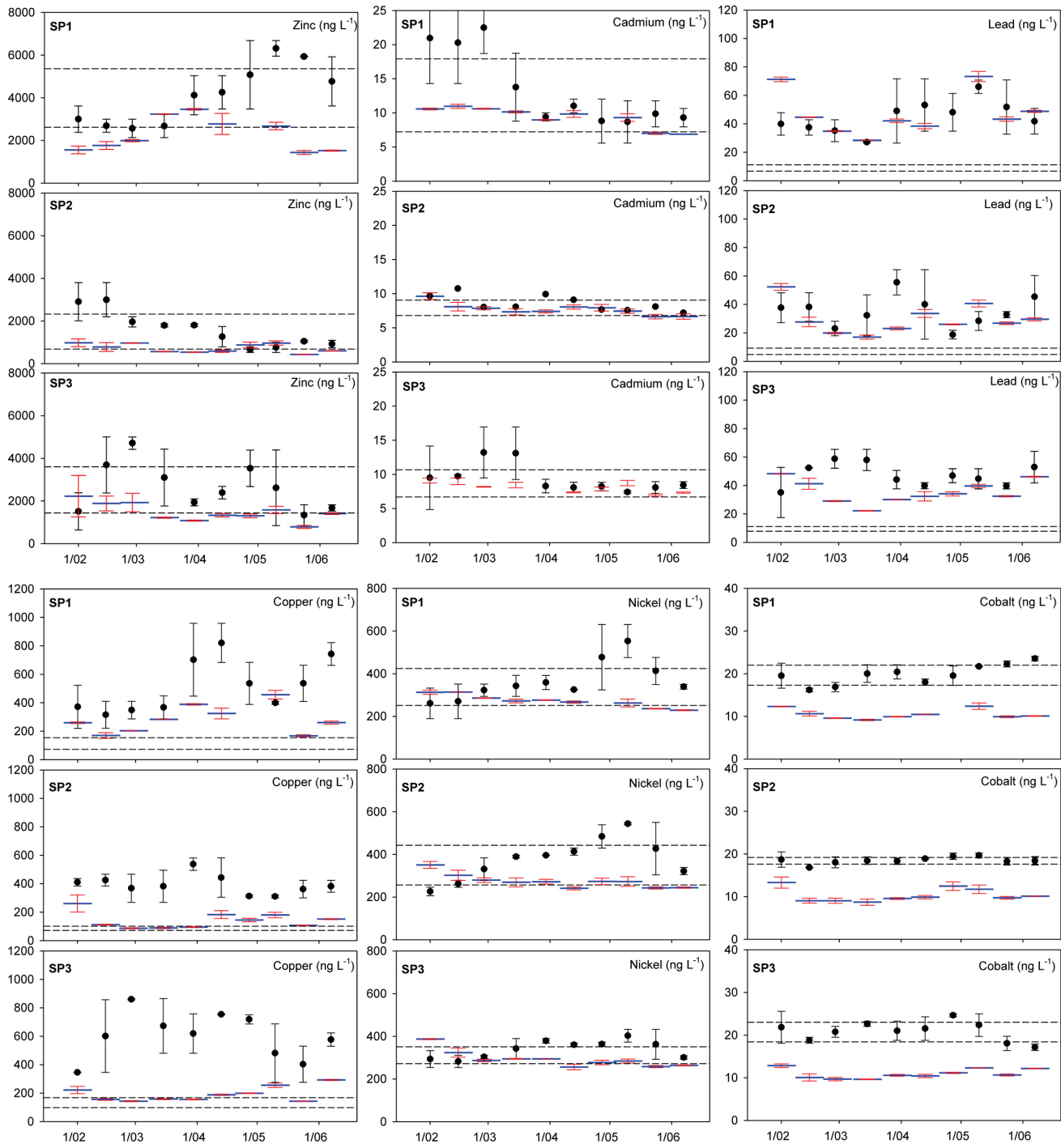

Figure 2. Temporal distribution of trace metals for the 5-month deployment period for three sites: dissolved trace metals (black circles) and DGT-labile trace metals (blue line). "Error bars" represent upper and lower concentrations of metals for the two consecutive discrete samplings (dissolved metals) or upper and lower concentrations for two DGT devices. Horizontal lines represent upper and lower limits of dynamic (labile) concentration of trace metals modeled using Visual Minteq (NICA-Donnan model; details provided in the main text). Note that "error bars" are NOT related to any uncertainty.

organic matter interactions. ${ }^{[36]}$ Seawater salinity of 36 (assumed as average for the DGT depth layer) and measured DOC concentrations were used as a typical sample composition.

\section{RESULTS AND DISCUSSION \\ Spatio-temporal Distribution of Dissolved Trace Metals}

The temporal distributions of dissolved trace metals were presented in Figure 2 by black circle symbols, whereas in
Table 1 average values were provided. As can be seen from Figure 2, there is no common pattern of variability of trace metal concentrations among the consecutive samplings and three sites. Cobalt ( $\mathrm{Co}$ ) and nickel (Ni) consecutive variability was very low at all three sites for the entire 5month period. Other trace metal concentrations fluctuated with periods of relatively high concentration variability between two sampling events but there was no discernible pattern for all metals and sites. For example, while very high variability was measured for cadmium (Cd) for the first four deployment periods at sites SP1 and SP3, relatively low 
Table 1. Average ( \pm standard deviation) concentrations of dissolved and DGT-labile trace metals, dissolved organic carbon (DOC) for the 5-month period and corresponding percentage of DGT-labile fraction

\begin{tabular}{|c|c|c|c|c|c|c|c|c|c|}
\hline & \multicolumn{3}{|c|}{ Dissolved / ng L-1 } & \multicolumn{3}{|c|}{$\mathrm{DGT} / \mathrm{ng} \mathrm{L}^{-1}$} & \multicolumn{3}{|c|}{ \% DGT-labile } \\
\hline & SP1 & SP2 & SP3 & SP1 & SP2 & SP3 & SP1 & SP2 & SP3 \\
\hline $\mathrm{Zn}$ & $4140 \pm 1390$ & $1610 \pm 840$ & $2650 \pm 110$ & $2270 \pm 780$ & $683 \pm 180$ & $1470 \pm 430$ & $55 \pm 26$ & $45 \pm 27$ & $56 \pm 28$ \\
\hline $\mathrm{Cd}$ & $13.5 \pm 5.6$ & $8.6 \pm 1.2$ & $9.4 \pm 2.1$ & $9.4 \pm 1.5$ & $7.4 \pm 0.5$ & $8.0 \pm 0.8$ & $70 \pm 31$ & $90 \pm 16$ & $86 \pm 21$ \\
\hline $\mathrm{Pb}$ & $45 \pm 11$ & $35 \pm 10$ & $47 \pm 8$ & $47 \pm 15$ & $27 \pm 6$ & $36 \pm 8$ & $105 \pm 43$ & $84 \pm 39$ & $75 \pm 21$ \\
\hline $\mathrm{Cu}$ & $514 \pm 184$ & $393 \pm 67$ & $603 \pm 160$ & $278 \pm 98$ & $122 \pm 35$ & $191 \pm 51$ & $54 \pm 27$ & $36 \pm 15$ & $32 \pm 12$ \\
\hline $\mathrm{Ni}$ & $366 \pm 91$ & $379 \pm 97$ & $339 \pm 41$ & $274 \pm 31$ & $262 \pm 16$ & $293 \pm 39$ & $74 \pm 20$ & $72 \pm 20$ & $86 \pm 16$ \\
\hline Co & $19.8 \pm 2.3$ & $18.5 \pm 0.8$ & $20.9 \pm 2.3$ & $10.5 \pm 1.1$ & $9.6 \pm 1$ & $10.9 \pm 1.1$ & $53 \pm 8$ & $56 \pm 9$ & $52 \pm 8$ \\
\hline $\mathrm{DOC} / \mathrm{mg} \mathrm{L}^{-1}$ & $0.95 \pm 0.14$ & $1.00 \pm 0.20$ & $1.11 \pm 0.32$ & & & & & & \\
\hline
\end{tabular}

variability was found for the same period at site SP2. Such specific variability patterns clearly show the overall dynamics of trace metal concentrations at the study area, but also demonstrates that the discrete sampling methodology, most widely used in environmental monitoring programs and research studies, ${ }^{[2,3,37,38]}$ is not ideal for (highly) dynamic aquatic systems. ${ }^{[39-41]}$

Examining the entire 5-month period, specific trends of trace metal concentrations varied by metals and sites. There was no clear correlation (Pearson's coefficient; all samples/sites) found between the metals. There were few statistically significant correlations ( $R$ _critical $=0.367 ; 95 \%$ level of significance, $n=29$ ) among metals, but here we defined 0.7 , as the limit of well-defined correlation. When examining each site separately, there were many more correlations between metals (see Tables S1a, S1b, and S1c). However, examining the similarity between all three sites for each metal separately, the only significant correlations was found for $\mathrm{Ni}$ (coefficients higher than 0.81). This is clearly visible in Figure 2 where the same trends of $\mathrm{Ni}$ concentrations were found for all three sites, indicating common long-term fluctuations in $\mathrm{Ni}$ concentrations for the studied area.

The absence of better correlations for the other metals among the three sites can be explained by the relatively uniform concentrations for the examined 5month period $(\mathrm{Co})$, or apparent variability in trace metal concentrations among sites. Such a scenario is not unexpected considering that the studied area is under different activities, both at the sea and at port docks, which caused irregularity in trace metal concentrations, especially those $(\mathrm{Zn}, \mathrm{Pb}, \mathrm{Cu})$ which are commonly considered as anthropogenic ones. The highest variability in dissolved trace metal concentrations was found at the site SP1. This is probably a result of the freshwater inflow from the "Dead channel" which is under greater anthropogenic pressure upstream. It should be mentioned that at SP1 there were significant quantities of floating particles of various size. According to visual observation and specific smell, we suspect that the source is local municipal wastewater.

Considering the mentioned inflow and other harbor activities, it was unexpected that the absolute concentration level of all metals was relatively low. While only slightly higher concentrations were evidenced for $\mathrm{Zn}$ and $\mathrm{Pb}$, concentrations of other metals were at the level of unpolluted coastal regions in the Adriatic, out of direct impact from harbor/marina activities. ${ }^{[2,9,42]}$ In addition to trace metals, concentrations of dissolved organic carbon (DOC) were also low and at the level of unpolluted regions ${ }^{[2]}$ ( $\approx 1 \mathrm{mg} \mathrm{C} \mathrm{L}{ }^{-1}$; see Figure S2 in supporting materials).

\section{DGT-labile Concentrations of Trace Metals}

As mentioned previously, the benefit of using passive sampling technique is the "integrative" nature, providing time-weighted average (TWA) DGT-labile concentrations of trace metals for the period of deployment. $[7,24,43]$ Accordingly, the variability of DGT-labile concentrations over the examined period ( 5 months) is expected to be lower compared to dissolved trace metal concentrations, as observed in this study (Figure 2, blue lines). Relatively low inter-variability (good repeatability) between the two DGT devices (side by side) were obtained in most cases (small error bars plotted in red). Slightly higher variability for $\mathrm{Zn}$ in some cases was probably caused by relatively high (up to $50 \%$ ) and unstable DGT-blank. If calculated for all sites, correlations were found only between $\mathrm{Cu}$ and $\mathrm{Zn}$ (0.76) and $\mathrm{Cu}$ and $\mathrm{Pb}$ (0.73), whereas when sites were analyzed separately, more metals had significant correlations (Tables S2a, S2b and S2c). Separate evaluation of each metal among the three sites showed that the observed trends in DGT-labile concentrations over the studied period were very similar for $\mathrm{Cd}, \mathrm{Pb}, \mathrm{Ni}$ and $\mathrm{Co}$, indicating a common (mean) behavior of each metal within the studied area. The absence of a common correlation for $\mathrm{Zn}$ and $\mathrm{Cu}$ was most likely caused by the variability observed at site SP1, which was much more dynamic (freshwater inflow by "Dead channel") compared to other two sites. 
For short term studies, which include collection of composite samples over the deployment period or for sites with relatively stable and expressed concentration gradient of trace metals, high degrees of correlation were found between dissolved and DGT-labile concentrations. ${ }^{[22,24,33,40,44]}$ In our study this was not the case. The only common characteristic for all metals was the lower average concentration of both dissolved and DGT-labile concentrations of trace metals at site SP2 compared to SP1 and SP3, over the duration of the study. Even though for some periods single dissolved concentrations were lower (but overlapping within the error bar) than the DGT-labile, with the exceptions of $\mathrm{Pb}$ at the site $\mathrm{SP} 1$, the average concentrations of DGT-labile metals were lower than corresponding dissolved concentrations. The percentage of DGT-labile concentrations are presented in Table 1. The lowest fraction of DGT-labile concentrations was measured for $\mathrm{Cu}$, while the highest for $\mathrm{Cd}$ and, unexpectedly for $\mathrm{Pb}$. These fractions reflect the chemical speciation of metals in seawater, which is controlled by their interactions with natural organic matter and anions (hydroxide, chloride, carbonate, sulfate). Among the examined metals, $\mathrm{Cu}$ is known to form the strongest complexes with organic ligands which are not effectively accumulated by the DGTresin. ${ }^{[22,36]}$ Conversely, $C d$ in seawater forms predominantly inorganic complexes with chloride which are labile and thus quantitatively accumulated by DGT device. ${ }^{[33,45]}$ The DGTlabile fractions obtained in this study are very similar to those we obtained in the Krka River estuary $(\approx 5$ days deployment period and composite sample), ${ }^{[34]}$ and agree with results of other authors. ${ }^{[45]}$ Thus, for the common practice, once estimated for the studied region, these ratios and measured DGT-labile concentration could be used to assess the average concentration of dissolved trace metals, a primary measure adopted for water quality control in monitoring studies according to EU Water Framework Directive (WFD). [19]

The advantage of using DGT devices is their ability to measure TWA concentration over the deployment period providing a more representative "fingerprint" of trace metal concentrations. This technique, however, prevents the possibility of recording potential short-term contamination issues. Yet, discrete sampling methodology allows such a scenario only if the sampling is performed frequently (at least on daily basis). For monitoring studies, this is not the case, therefore, passive sampling is a better approach for highly variable systems.

The added value of using DGT devices is that they provide information regarding the concentration that is considered as potentially bioavailable, and can be applied in the studies of metal uptake by biota. ${ }^{[46-48]}$ Several studies found that the accumulation of metals within the biota corresponds more to DGT-labile than to dissolved concentration of trace metals. ${ }^{[10,45,49]}$ Bioavailability is also the term adopted by the WFD, either by a direct measurement or calculated by the speciation modeling, and it is suggested as Environmental quality standard (EQS). The concept of bioavailability, realized through the Biotic Ligand Model (BLM) ${ }^{[26,50,51]}$ is fully implemented as the water quality parameter for $\mathrm{Cu}$ in US EPA ${ }^{[27]}$ and is widely in test-use across the EU countries. ${ }^{[52]}$ This methodology relies primarily on the experimentally derived stability constants of metal complexes deposited in databases, and in practice is implemented through the chemical speciation calculations for predefined set of parameters using dedicated speciation modeling software. ${ }^{[35,53,54]}$ In addition to the concentration of dissolved trace metal and major anions/cations, the main input parameter for BLM is the concentration of dissolved organic carbon (DOC). In our work, we applied a similar strategy and modeled the chemical speciation in order to predict the dynamic (labile) concentration of trace metals and to compare to the DGTlabile.

\section{Comparison of DGT-labile and Predicted Dynamic Metal Concentrations}

DGT is known as the "dynamic" speciation technique due to the fact that the uptake (accumulation) of trace metals is dependent on the dissociation kinetics of metal complexes within the diffusion layer/gel. ${ }^{[7,45,55,56]}$ Thus, the thermodynamic consideration of the speciation calculations does not necessarily reflect the real processes at DGT/water interface which are partially or fully under kinetical control.[55] Accordingly, the DGT technique is considered "operational" because it depends on the actual physico-chemical conditions. In order to compare the operationally measured DGT-labile concentrations with those predicted by the speciation modeling, we adopted the approach used in work of Han et al.[45] For the calculation of the predicted DGT-labile concentration of metals the following equation was used:

$$
C_{\text {pred }}=C_{\text {inorg }}+\frac{C_{\mathrm{FA}} D_{\mathrm{FA}}}{D_{\text {inorg }}}+\frac{C_{\mathrm{HA}} D_{\mathrm{HA}}}{D_{\text {inorg }}} .
$$

$C_{\mathrm{FA}}, C_{\mathrm{HA}}$ and $D_{\mathrm{FA}}, D_{\mathrm{HA}}$ are concentrations of metal complexes with fulvic (FA) and humic (HA) acids, and corresponding diffusion coefficients, respectively. For this purpose, diffusion coefficients for metal complexes with FA and HA are assumed to be the same as for FA $\left(1.15 \times 10^{-6} \mathrm{~cm}^{2} \mathrm{~s}^{-1}\right)$ and $\mathrm{HA}\left(0.6 \times 10^{-6} \mathrm{~cm}^{2} \mathrm{~s}^{-1}\right)$ itself. These diffusion coefficients are taken from Zhang. ${ }^{[57]}$ Typical seawater composition of salinity 36 was used for the major anion and cation concentrations, while the average DOC for each site was used. Modelling of interactions of metals with organic ligands was performed by NICA-Donnan model (NICA). It 
was considered that $90 \%$ of the organic matter is represented by FA and $10 \%$ by HA. No other adaptation of default parameters was undertaken. The two, high and low limit concentrations of dissolved trace metals used for the calculation were obtained by adding or subtracting one standard deviation from the average value.

The obtained range of predicted DGT-labile (dynamic) concentrations for these conditions is presented in Figure 2 and lies between the two dashed lines, representing the upper and the lower limits. Predicted ranges of DGT-labile concentrations for $\mathrm{Cd}, \mathrm{Ni}$ and partially for $\mathrm{Zn}$ were in relatively good accordance with the range of measured DGTlabile concentrations. However, for $\mathrm{Pb}$ and $\mathrm{Cu}$, the predicted dynamic concentration range was lower than the measured DGT range, while for $\mathrm{Co}$, an overestimation of the dynamic concentration was predicted. Similar relationships between predicted and measured DGT-labile concentrations were obtained in a study performed at the Krka River estuary, ${ }^{[34,44]}$ with the main difference for $\mathrm{Pb}$, for which the predicted DGT concentration was around $60 \%$ of the measured one. While in many studies a quite good correlation coefficients between measured and predicted DGT-labile concentrations were found (same trends over wide range of concentrations), the agreement between their absolute values was very variable. ${ }^{[24,33,45]}$ As we examined here only one level of concentrations (average values) for each site, there was no sufficient data to perform such correlation analysis.

Based on the applied modelling approach, it is evident that organic complexes are partly accumulated by DGT. The actual question is about the "sources" of disagreement between measured and predicted DGT-labile concentrations. Basically, in our calculations it is assumed that DOC is $90 \% \mathrm{FA}$ and $10 \% \mathrm{HA}$ and that all metal complexes with FA and HA are labile and accessible to DGT, but having different diffusion coefficient which are smaller than those of metals. ${ }^{[55,58]}$ Recently, Balch and Guéguen ${ }^{[59]}$ showed that diffusion coefficients for "bulk" dissolved organic matter and humic substances (HS) are 2-3 times higher than values we used in our calculations. For calculations of the average metal diffusion coefficient, Uher et al. ${ }^{[60]}$ applied slightly higher diffusion coefficients (from $1.8 \times 10^{-6} \mathrm{~cm}^{2} \mathrm{~s}^{-1}$ to $2.8 \times 10^{-6} \mathrm{~cm}^{2} \mathrm{~s}^{-1}$ ). Thus, it is possible to assume that effective diffusion coefficients for metal complexes with organic ligands (FA and HA) should be applied and not equalized to the uncomplexed FA and HA. As mentioned previously, if metal complexes are not fully labile, the dissociation kinetics, rather than diffusion, controls the accumulation process. ${ }^{[55,58]}$

Generally better agreements between measured and predicted DGT-labile concentrations were found in studies performed in rivers. ${ }^{[22,24,33,45,61]}$ This is expected because the modelling of metal-organic ligand interactions incorporated in programs are developed on the basis of data collected primarily in studies performed in freshwater environments. Accordingly, predefined parameters for FA and $\mathrm{HA}$ interactions with metals are not specific for marine, but for continental/terrestrial environments, and thus marine organic ligands can have quite different reactivity due to different sources (e.g. mainly produce by marine micro-organisms) and chemical composition, which would require to better characterize the specific complexation properties of marine organic matter. Thus, the prediction of metal speciation in marine environments is still a challenging task, demanding the extensive and more focused studies.

\section{CONCLUDING REMARKS}

Discrete and passive sampling (DGT) methodology, combined with chemical speciation modeling (Visual Minteq; NICA-Donnan) were evaluated for the determination of spatial and temporal distribution of trace metals within a small marine harbor area (three sampling sites). Relatively low concentrations of dissolved trace metals, comparable to those found in the coastal region of the Adriatic, were found and are below the acute threshold values estimated as protective for coastal areas according to marine water quality criteria.[18] Average concentrations of trace metals measured with DGT passive samplers were lower compared to dissolved concentrations measured in discrete samples, indicating that they accumulated only a limited fraction of the total metal. When averaged across the 5-month period, both methods provided the same pattern of spatial distribution for all trace metals within the examined port. The complementarity of these two approaches lies in a fact that the classical discrete sampling provides insight into the total level of trace metals, while DGT-labile concentrations relates to the potentially bioavailable fraction ${ }^{[11,45]}$ and reflect the speciation of trace metals, particularly regarding natural organic matter interactions. Chemical speciation modeling provided a good estimation of dynamic concentrations (predicted DGT-labile) only for some trace metals: estimations for $\mathrm{Cd}, \mathrm{Zn}$ and $\mathrm{Ni}$ agreed well with the measured, whereas for $\mathrm{Pb}, \mathrm{Cu}$ and $\mathrm{Co}$ this was not the case. Thus, more dedicated studies, combining different modeling parameters and experimental data should be undertaken to advance the modeling methodology. This inter-methodology study demonstrates that passive sampling can be an efficient method for monitoring of trace metals, in compliance with the Water Framework Directive (WFD) and Marine Strategy Framework Directive (MSFD). 
Acknowledgment. This work was carried out in the partnership with the Port of Rijeka Authority. Their financial and logistical support is greatly acknowledged. The research study was conducted within the scope of the project "New methodological approach to biogeochemical studies of trace metal speciation in coastal aquatic ecosystems" supported by the Croatian Science Foundation under the project number IP-2014-09-7530 (PI: D.O.). We would like to thank Renée Bishop (Pennsylvania State University, Dunmore, USA) for English corrections and final improvement of the manuscript.

\section{REFERENCES}

[1] J. Gaillardet, J. Viers, B. Dupré, Trace elements in river waters, in Surface and ground water, weathering, and soils, H. D. Holland and K. K. Turekian (Eds.), 2004, Elsevier, pp. 225-272.

[2] A. M. Cindric, C. Garnier, B. Oursel, I. Pizeta, D. Omanovic, Mar. Pollut. Bull. 2015, 94, 199.

[3] V. N. Deycard, J. Schäfer, G. Blanc, A. Coynel, J. C. J. Petit, L. Lanceleur, L. Dutruch, C. Bossy, A. Ventura, Mar. Chem. 2014, 167, 123.

[4] B. Oursel, C. Garnier, G. Durrieu, S. Mounier, D. Omanovic, Y. Lucas, Mar. Pollut. Bull. 2013, 69, 137.

[5] K. W. Bruland, M. C. Lohan, Controls of trace metals in seawater, in Treatise on geochemistry, H. D. Holland and K.K. Turekian (Eds.), 2004, Pergamon: Oxford, p. 23.

[6] I. A. M. Ahmed, J. Hamilton-Taylor, M. Bieroza, Z. Zhang, W. Davison, Water Res. 2014, 67, 276.

[7] W. Davison, H. Zhang, Environ. Chem. 2012, 9, 1.

[8] W. Davison, H. Zhang, Nature 1994, 367, 546.

[9] V. Cuculić, N. Cukrov, Z. Kwokal, M. Mlakar, Estuar. Coast. Shelf S. 2009, 81, 311.

[10] A. Caillat, P. Ciffroy, M. Grote, S. Rigaud, J. M. Garnier, Environ. Toxicol. Chem. 2014, 33, 278.

[11] D. Ferreira, P. Ciffroy, M. H. Tusseau-Vuillemin, A. Bourgeault, J. M. Gamier, Chemosphere 2013, 91, 241.

[12] J. Forsberg, R. Dahlqvist, J. Gelting-Nystrom, J. Ingri, Environ. Sci. Technol. 2006, 40, 3901.

[13] L. A. Miller, K. W. Bruland, Anal. Chim. Acta, 1997, 343, 161.

[14] K. W. Bruland, E. L. Rue, J. R. Donat, S. A. Skrabal, J. W. Moffett, Anal. Chim. Acta, 2000, 405, 99.

[15] C. Garnier, S. Mounier, J. Y. Benaïm, Environ. Technol. 2004, 25, 589.

[16] Y. Louis, C. Garnier, V. Lenoble, S. Mounier, N. Cukrov, D. Omanović, I. Pižeta, Mar. Chem. 2009, 114, 110.

[17] D. Omanović, I. Pižeta, Ž. Peharec, M. Branica, Mar. Chem. 1996, 53, 121.
[18] I. Duran, R. Beiras, Sci. Total Environ. 2013, 463, 446.

[19] Directive 2013/39/EU, [Official J L 226/ 24/08/2013]. 2013.

[20] I. Pizeta, S. G. Sander, R. J. M. Hudson, D. Omanovic, O. Baars, K. A. Barbeau, K. N. Buck, R. M. Bundy, G. Carrasco, P. L. Croot, C. Garnier, L. J. A. Gerringa, M. Gledhill, K. Hirose, Y. Kondo, L. M. Laglera, J. Nuester, M. J. A. Rijkenberg, S. Takeda, B. S. Twining, M. Wells, Mar. Chem. 2015, 173, 3.

[21] A. H. Shiva, W. W. Bennett, D. T. Welsh, P. R. Teasdale, Environ. Sci.-Proc. Imp. 2016, 18, 51.

[22] K. W. Warnken, W. Davison, H. Zhang, Environ. Sci. Technol. 2008, 42, 6903.

[23] W. J. G. M. Peijnenburg, P. R. Teasdale, D. Reible, J. Mondon, W. W. Bennett, P. G. C. Campbell, Integr. Environ. Assess. Manage. 2014, 10, 179.

[24] E. R. Unsworth, K. W. Warnken, H. Zhang, W. Davison, F. Black, J. Buffle, J. Cao, R. Cleven, J. Galceran, P. Gunkel, E. Kalis, D. Kistler, H. P. Van Leeuwen, M. Martin, S. Noel, Y. Nur, N. Odzak, J. Puy, W. Van Riemsdijk, L. Sigg, E. Temminghoff, M. L. Tercier-Waeber, S. Toepperwien, R. M. Town, L. P. Weng, H. B. Xue, Environ. Sci. Technol. 2006, 40, 1942.

[25] E. D. Amato, S. L. Simpson, C. V. Jarolimek, D. F. Jolley, Environ. Sci. Technol. 2014, 48, 4485.

[26] D. M. Di Toro, H. E. Allen, H. L. Bergman, J. S. Meyer, P. R. Paquin, R. C. Santore, Environ. Toxicol. Chem. 2001, 20, 2383.

[27] US-EPA, Aquatic life ambient freshwater quality criteria - copper, 2007.

[28] L. D. F. Costa, M. R. D. Casartelli, M. WallnerKersanach, Quim. Nova, 2013, 36, 1089.

[29] G. Neser, A. Kontas, D. Unsalan, E. Uluturhan, O. Altay, E. Darilmaz, F. Kucuksezgin, N. Tekogul, F. Yercan, Mar. Pollut. Bull. 2012, 64, 882.

[30] A. Abbott, P. D. Abel, D. W. Arnold, A. Milne, Sci. Total Environ. 2000, 258, 5.

[31] A. Jessop, A. Turner, Chemosphere 2011, 83, 1575.

[32] N. Singh, A. Turner, Environ. Pollut. 2009, 157, 371.

[33] D. Omanovic, I. Pizeta, P. Vukosav, E. Kovacs, S. Franciskovic-Bilinski, J. Tamas, Sci. Total Environ. 2015, 511, 423.

[34] A.-M. Cindrić, B. Oursel, N. Cukrov, C. Garnier, I. Pižeta, D. Omanović, in preparation, 2017.

[35] J. P. Gustafsson, Visual MINTEQ ver. 3.1. , 2011, https://vminteq.Iwr.kth.se/.

[36] D. G. Kinniburgh, C. J. Milne, M. F. Benedetti, J. P. Pinheiro, J. Filius, L. K. Koopal, W. H. VanRiemsdijk, Environ. Sci. Technol. 1996, 30, 1687.

[37] B. Oursel, C. Gamier, M. Zebracki, G. Durrieu, I. Pairaud, D. Omanovic, D. Cossa, Y. Lucas, Mar. Chem. 2014, 167, 44. 
[38] B. Oursel, C. Garnier, I. Pairaud, D. Omanovic, G. Durrieu, A. D. Syakti, C. Le Poupon, B. Thouvenin, Y. Lucas, Estuar. Coast. Shelf S. 2014, 138, 14.

[39] C. Priadi, A. Bourgeault, S. Ayrault, C. GourlayFrance, M. H. Tusseau-Vuillemin, P. Bonte, J. M. Mouchel, J. Environ. Monit. 2011, 13, 1470.

[40] I. J. Allan, J. Knutsson, N. Guigues, G. A. Mills, A. M. Fouillac, R. Greenwood, J. Environ. Monit. 2008, 10, 821.

[41] J. Knutsson, S. Rauch, G. M. Morrison, Int. J. Anal. Chem. 2014, ID 389125.

[42] S. P. C. Tankere, P. J. Statham, Mar. Pollut. Bull. 1996 32, 623.

[43] N. Montero, M. J. Belzunce-Segarra, J. L. Gonzalez, J. Larreta, J. Franco, Mar. Pollut. Bull. 2012, 64, 31.

[44] A.-M. Cindrić, PhD Thesis, 2015.

[45] S. P. Han, Y. Zhang, S. Masunaga, S. Y. Zhou, W. Naito, Environ. Pollut. 2014, 189, 215.

[46] C. Lafabrie, G. Pergent, R. Kantin, C. Pergent-Martini, J. L. Gonzalez, Chemosphere 2007, 68, 2033.

[47] J. Richir, N. Luy, G. Lepoint, E. Rozet, A. A. Azcarate, S. Gobert, Aquat. Toxicol. 2013, 140, 157.

[48] A. Bourgeault, P. Ciffroy, C. Garnier, C. CossuLeguille, J. F. Masfaraud, R. Charlatchka, J. M. Garnier, Sci. Total Environ. 2013, 452-453, 68.

[49] M. S. Kim, M. S. Choi, C. K. Kim, Ocean Sci. J. 2016, 51, 169.

[50] P. R. Paquin, J. W. Gorsuch, S. Apte, G. E. Batley, K. C. Bowles, P. G. C. Campbell, C. G. Delos, D. M. Di
Toro, R. L. Dwyer, F. Galvez, R. W. Gensemer, G. G. Goss, C. Hogstrand, C. R. Janssen, J. C. McGeer, R. B. Naddy, R. C. Playle, R. C. Santore, U. Schneider, W. A. Stubblefield, C. M. Wood, K. B. Wu, Comp. Biochem. Phys. C 2002, 133, 3.

[51] M. M. Ardestani, N. M. van Straalen, C. A. M. van Gestel, Environ. Pollut. 2014, 195, 133.

[52] H. Rudel, C. D. Muniz, H. Garelick, N. G. Kandile, B. W. Miller, L. P. Munoz, W. J. G. M. Peijnenburg, D. Purchase, Y. Shevah, P. van Sprang, M. Vijver, J. P. M. Vink, Environ. Sci. Pollut. Res. 2015, 22, 7405.

[53] HydroQual-Inc, Biotic Ligand Model, Version 2.2.3, 2007.

[54] Bio-met, 2017, Bioavailability of metals and the WFD.

[55] S. Scally, W. Davison, H. Zhang, Environ. Sci. Technol. 2003, 37, 1379.

[56] H. P. van Leeuwen, R. M. Town, J. Buffle, R. F. M. J. Cleven, W. Davison, J. Puy, W. H. van Riemsdijk, L. Sigg, Environ. Sci. Technol. 2005, 39, 8545.

[57] H. Zhang, Environ. Sci. Technol. 2004, 38, 1421.

[58] M. R. S. Arvajeh, N. Lehto, O. A. Garmo, H. Zhang, Environ. Sci. Technol. 2013, 47, 463.

[59] J. Balch, C. Gueguen, Chemosphere 2015, 119, 498.

[60] E. Uher, M. H. Tusseau-Vuillemin, C. Gourlay-France, Environ. Sci.-Proc. Imp. 2013, 15, 1351.

[61] S. Meylan, N. Odzak, R. Behra, L. Sigg, Anal. Chim. Acta 2004, 510, 91. 